\title{
Effects of Partial Supporting Pile Removal from Deep Foundation Pits by Shallow Excavation Method in Loess Areas
}

\author{
Yunxin Zheng $\mathbb{D}^{1},{ }^{1}$ Zhiping Hu $\mathbb{D}^{1,2}$ Xiang Ren, ${ }^{1}$ Rui Wang $\mathbb{D}^{1},{ }^{1}$ Enxiang Zhang, \\ and Zhao Long $^{3}$ \\ ${ }^{1}$ School of Civil Engineering, Chang'an University, Xi'an 710061, China \\ ${ }^{2}$ Institute of Underground Structure and Engineering, Chang'an University, Xi'an 710061, China \\ ${ }^{3}$ Gansu CSCEC Municipal Engineering Investigation and Design Institute Co. LTD., Lanzhou, Gansu 730000, China
}

Correspondence should be addressed to Zhiping Hu; huzhping@chd.edu.cn

Received 23 March 2021; Revised 30 June 2021; Accepted 30 July 2021; Published 29 August 2021

Academic Editor: Antonio Gloria

Copyright ( 92021 Yunxin Zheng et al. This is an open access article distributed under the Creative Commons Attribution License, which permits unrestricted use, distribution, and reproduction in any medium, provided the original work is properly cited.

Partial supporting piles removal from deep foundation pit may lead to large-scale foundation pit collapse, resulting in severe consequences. Various studies have investigated the underpinning technology of cutting abutment piles by combining field monitoring and numerical simulation, but there are few studies on cutting supporting piles of foundation pit by the shallow excavation method. Taking an actual deep and large foundation pit as an example, the finite element method (FEM) was adopted to study the surface settlement and the changing trend of the force and displacement of the supporting pile caused by cutting piles during the shallow excavation of double tunnels. The FEM results were verified with the field monitoring data. The simulation results show that the surface settlement around the foundation pit mainly occurs at the pile cutting stage under different excavation sequences $(0 \mathrm{D}, 1 \mathrm{D}, 2 \mathrm{D})$, and the main distribution area is the one-fold diameter area outside the double tunnel. After the supporting piles are partially cut, the bending moment and displacement of the lower part of the broken piles differ significantly due to different excavation sequences, but the bending moment and displacement of the upper part of the broken piles are basically similar. In the process of removing the supporting piles, the Earth pressure behind the piles is redistributed, and the load is mainly transferred to the adjacent supporting piles outside the tunnel within the radius of one time of the tunnel diameter. However, the load is not evenly transferred to the adjacent supporting piles. Some recommendations for the reinforcement scheme of the supporting structure during cutting supporting piles in deep foundation pit are also proposed. The research results can provide theoretical basis and practical guidance for the construction of similar projects in the future.

\section{Introduction}

Deep excavation engineering is widely applied in the construction of high-rise buildings, metro stations, and underground transportation centers. With the growth of urbanization, the construction scale of single excavation projects is becoming increasingly large and complex [1]. This creates difficulties in the process of foundation pit excavation. Monitoring of the soil deformation adjacent to excavations and the internal force of support structures is vital to obtain necessary information regarding the mechanical behavior of supporting systems and soil masses [2-20]. However, during the foundation pit excavation process, the overall stability of the foundation pit, the stress deformation of the supporting structure, and the surface settlement around the pit are continuously balanced in a dynamic manner. The formation conditions and surrounding environment are highly complex, and previous experience is not easily replicated. The research only using the field monitoring method is generally only reflected in the statistical analysis of the displacement of the supporting structure and the soil deformation behind the pile. For the limitations of research methods, the complexity of foundation pit engineering and the interaction between foundation pit excavation and surrounding structures cannot be fully considered. Therefore, the discussion on the mechanical mechanism of the interaction between the supporting structure and soil mass is still inadequate. 
Numerical simulation is an accurate and convenient approach for complex systematic analysis in the foundation pit engineering field. Numerical simulations are repeatable, reveal systemic mechanical behavior during an excavation process, and can be compared against monitoring data to obtain meaningful analysis results [21, 22]. Certain mechanical aspects of foundation pit supporting structures under different engineering conditions can be validated by numerical simulations.

Based on a series of three-dimensional (3D) numerical simulation models in the soft soil area, Shakeel and $\mathrm{Ng}$ [23] studied the effects of foundation pit depth, pile length, and pile group position on foundation pit excavation and supporting system stiffness. Zhang et al. [24] experimentally and numerically investigated the interaction between foundation pit surrounding structures and a retaining structure during the excavation process. Guo et al. [25] assessed the displacement and supporting structure stress characteristics of deep foundation pits under asymmetric loads via numerical analysis. Liu et al. [26] used a numerical model to study the supporting scheme and mechanical properties of a deep foundation pit under asymmetric loading. Gao et al. [27] developed a model for computing supporting structure deformation in circular foundation pits.

Most studies on foundation pit engineering are focused on the stability of the pit and the interaction between the pit and its surrounding buildings. During construction of foundation pits for urban underground space development purposes, shallow-buried excavation or pipe jacking inevitably cuts off a portion of the foundation pit supporting piles, but its impacts are not yet fully understood. The supporting structure system of the foundation pit is changed after the piles are partially removed. The effects of pile cutting such as load transfer, internal force, and deformation of the supporting structure are not clear. However, these factors can pose severe risks to the safety of the deep foundation pit.

The XingFuLinDai project in Xi'an City was taken as the background for the present study. A 3D numerical analysis model of cutting supporting piles during the shallow-buried excavation of double tunnels under different excavation spacing conditions was established and combined with field monitoring data. The load adjustment range, internal force variation range, and deformation distribution around the pit caused by cutting supporting pile were studied. Then, relevant engineering recommendations are given for the condition of cutting supporting piles by shallow-buried excavation. As a typical engineering problem that will surely continue to be encountered in the future, the general trends of load transfer, internal force, and deformation of the supporting structure after partial piles removal have considerable reference value.

\section{Project Background and Numerical Model}

2.1. Introduction to Case History. The deep excavation project used here as a case study is adjacent to XingFu road, an arterial road in Xi'an, China. Its plan layout is shown in Figure 1 . The excavation area is $81,200 \mathrm{~m}^{2}$, the main excavation depth is $17.5 \mathrm{~m}$, and the maximum excavation depth is $19 \mathrm{~m}$. The average ground water level for the project site is about $-20.5 \mathrm{~m}$. In the plan view, the shape of the excavation is approximately a rectangle. As shown in Figure 1, many existing buildings are located adjacent to the west side of the excavation at a minimum distance of only $20 \mathrm{~m}$. To control the deformation induced by the excavation and protect the surrounding buildings, the foundation was excavated layerby-layer over multiple steps. The northern part was excavated first, followed by excavation of the southern part. The northern side and the southern side were both supported by a pile-anchor supporting structure, but the north side was equipped with contiguous supporting piles (Ф1000@2200) different from the southern side (Ф1200@2200). Figure 1 also shows the monitored sections and points. " $G 1$ " is the point where ground settlement was monitored by punctuation with a circular reinforcement.

The main physical and mechanical parameters of the soil layer are shown in Figure 2. The construction of cutting piles occurs mainly in the paleosol layer (1). The first layer extending from the surface to $-2 \mathrm{~m}$ is the fill layer. The second layer, from -2 to $-12 \mathrm{~m}$, is loess (1). The third layer from -12 to $-19 \mathrm{~m}$ is paleosol (1), the fourth layer from -19 to $-30 \mathrm{~m}$ is loess (2), and the fifth layer from -30 to $-50 \mathrm{~m}$ is paleosol (2) containing a small amount of calcareous nodules. A geotechnical investigation was carried out prior to construction, including a series of laboratory tests and field tests. The distribution and parameters of each soil layer determined in the investigation are summarized in Table 1.

2.2. Supporting Structure Design. In the structure studied here, the excavation depth of $17.5 \mathrm{~m}$ is supported by a pile anchor. A row of supporting piles consists of reinforced bored piles $1 \mathrm{~m}$ in diameter, $23.5 \mathrm{~m}$ in length, and $2.2 \mathrm{~m}$ in pile spacing. To stiffen the supporting piles, a reinforced concrete crown beam connects the pile head with a $1.2 \mathrm{~m} \times 0.8 \mathrm{~m}$ rectangular section. Supporting piles are reinforced by three rows of anchors consisting of four strands with a $15^{\circ}$ design angle. According to National Bureau of Standards (NBS) (GB/T5224-2014) [28], each strand has a total cross-sectional area of $1.4 \times 10^{-4} \mathrm{~m}^{2}$ with a nominal diameter of $15.2 \mathrm{~mm}$, consisting of four wires with $5 \mathrm{~mm}$ diameter and $1860 \mathrm{MPa}$ strength. The vertical spacing of three rows of anchors is $4 \mathrm{~m}$, and the horizontal spacing of each row of anchors is $2.2 \mathrm{~m}$. The free length and fixed length of the anchors are shown in Figure 1.

Waist girder 1 and waist girder 2 are both made of $28 \mathrm{~B}$ double I-beam steel, and waist girder 3 is made of $32 \mathrm{~B}$ double I-beam steel. The tunnel lining is C35 concrete of $30 \mathrm{~mm}$ thickness. The pipe roof of the shallow-buried excavation tunnel is composed of hot-rolled steel tubes (108 $\mathrm{mm}$ in thickness) with a circumferential spacing of $400 \mathrm{~mm}$.

2.3. Numerical Model. ABAQUS commercial software was adopted to investigate the complex construction process. To eliminate the influence of the boundary on the calculation results and for the sake of efficiency, the dimensions of the model were set to $57.2 \mathrm{~m}$ length, $30 \mathrm{~m}$ width, and $50 \mathrm{~m}$ 


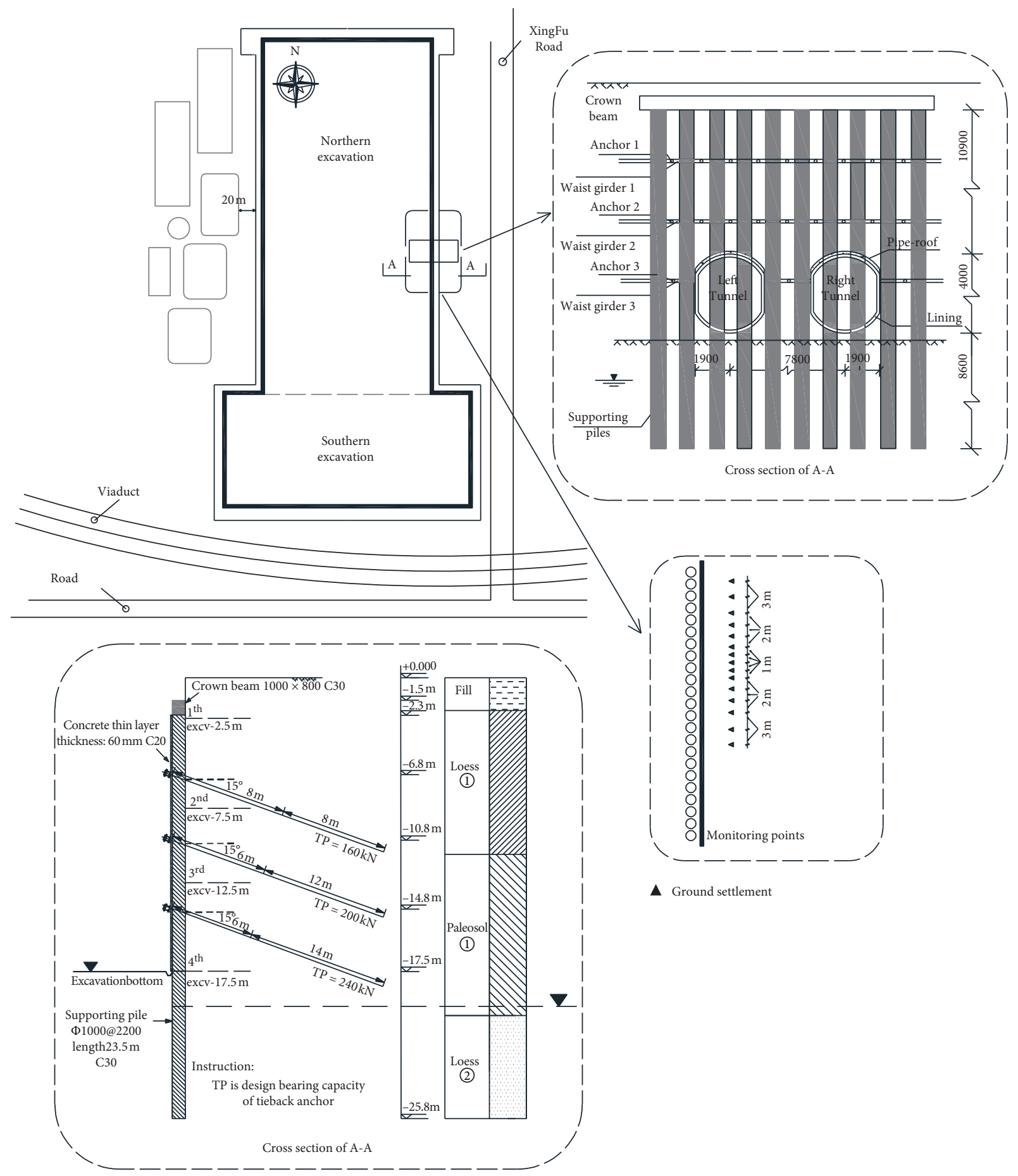

FIGURE 1: Soil profiles and supporting systems. Note: $\Phi=$ pile diameter and @=pile center-to-center spacing.

height, as shown in Figure 3. To prevent grid distortion and enhance the accuracy of the calculation, HYPERMESH preprocessing software was used to divide the grid to ensure the proper node alignment. The C3D8R solid element was used to simulate the soil layer of foundation pit, supporting pile, crown beam, lining, pipe roof, and concrete thin layer, while the anchor was simulated by the T3D2 truss element.

The small strain hardening soil (HSS) model is often used for finite element (FE) analysts to investigate soil behavior in excavation projects. The HSS accurately reflects soil stress history, but it is difficult to obtain reasonable model parameters due to a lack of field test data. Previous scholars have extensively researched the influence of constitutive models on foundation pit construction simulations $[29,30]$. The linear elastic-perfectly plastic constitutive model of Mohr-Coulomb, with reliable physical parameters, is used in the Abaqus software [31-34]. Thus, the constitutive soil model used in this study was the Mohr-Coulomb model.

The input parameters of the soils are shown in Table 1. The supporting piles, crown beam, lining, pipe roof, 


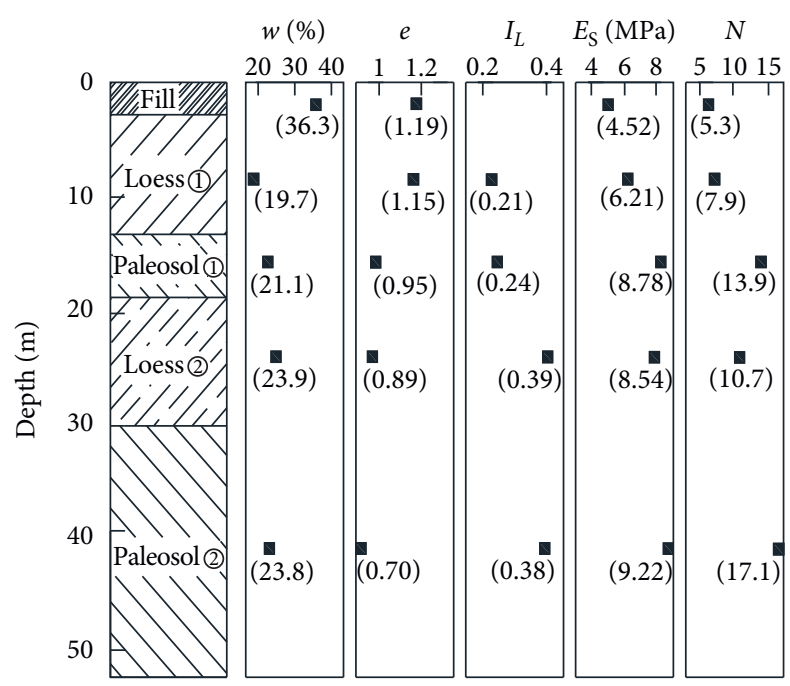

Figure 2: Geotechnical profile and soil properties of the construction site.

TABle 1: Physical and mechanical parameters of the soil layer.

\begin{tabular}{lccccccc}
\hline Layer no. & Soil type & Thickness $(\mathrm{m})$ & $\gamma\left(\mathrm{kg} / \mathrm{m}^{3}\right)$ & $E(\mathrm{MPa})$ & $\mu$ & $\varphi\left(^{\circ}\right)$ & $c(\mathrm{kPa})$ \\
\hline $1-1$ & Fill & 2 & 1600 & 6.00 & 0.35 & 15.00 \\
$2-1$ & Loess (1) & 10 & 1570 & 7.5 & 7.4 & 0.3 & 22.00 \\
$3-1$ & Paleosol (1) & 7 & 1929 & 8.15 & 0.3 & 22.00 \\
$2-2$ & Loess (2) & 11 & 1620 & 9.12 & 0.3 & 24.00 \\
$3-2$ & Paleosol (2) & 20 & 1990 & 26.00 & 34.00 \\
\hline
\end{tabular}

Note. $\gamma$ is the unit weight of the soils; $E$ is Young's modulus; $\mu$ is Poisson's ratio; $\varphi$ is the angle of internal friction; and, $c$ is the cohesion.

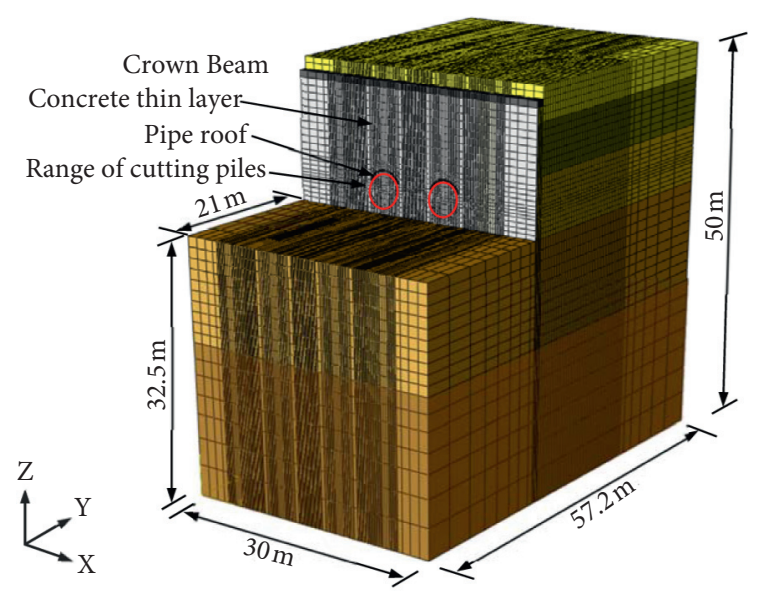

(a)

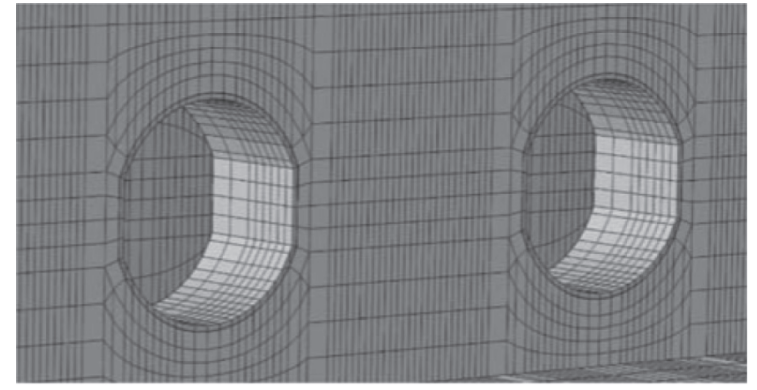

(b)

Figure 3: Perspective view of the developed numerical model. Perspective view (a). Enlarged view (b).

concrete thin layer, and anchors were formulated as a linear elastic model in the simulations. Young's modulus of the supporting pile, pipe roof, and crown beam was set to $30 \mathrm{GPa}$, and Poisson's ratio was set to 0.2. Young's modulus of tunnel lining was set as $35 \mathrm{GPa}$, and Poisson's ratio was set as 0.2 . The anchors were also modeled as the isotropic elastic material with Young's modulus and Poisson's ratio of $195 \mathrm{GPa}$ and 0.22 , respectively. The contact between soil and supporting piles was set as surface-to-surface contact. The top surface of the model is a free boundary, the periphery of the model is a normal constraint boundary, and the bottom of the model is a displacement constraint. The finite element model has 422,812 solid elements and 306 bar elements; the total number of nodes is 441,692.

The construction sequences adopted in the deep excavation are presented in Table 2 . The specific construction operations were simulated by setting state of activation and inactivation of the grid elements and the imposition and elimination of boundary conditions. 
TABLE 2: The construction sequences of deep excavation.

\begin{tabular}{lc}
\hline Sequences & Construction activities \\
\hline 1 & Construction of supporting piles \\
3 & Preexcavation and construction slopes (first excavation) \\
4 & Install row of anchor 1 and tensioning \\
5 & Second excavation \\
6 & Install row of anchor 2 and tensioning \\
7 & Third excavation \\
8 & Install row of anchor 3 and tensioning \\
9 & Fourth excavation \\
10 & Construct concrete thin layer on the side wall of pit and construct tunnel pipe roof \\
11 & Cut the supporting piles and remove soil around them \\
12 & Twin tunnel excavation (excavation $30 \mathrm{~m}, 2 \mathrm{~m}$ per footage) \\
\end{tabular}

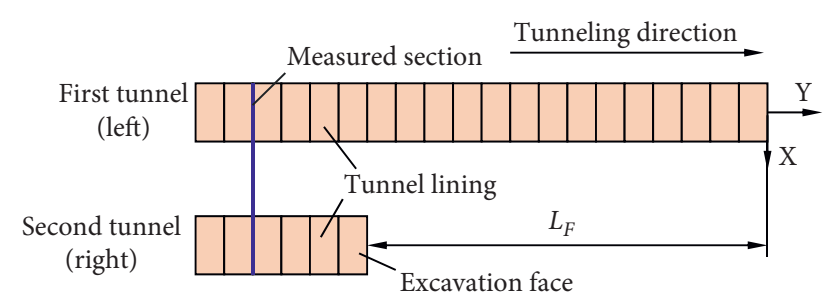

FIgure 4: Plan view of twin tunnels (not to scale).

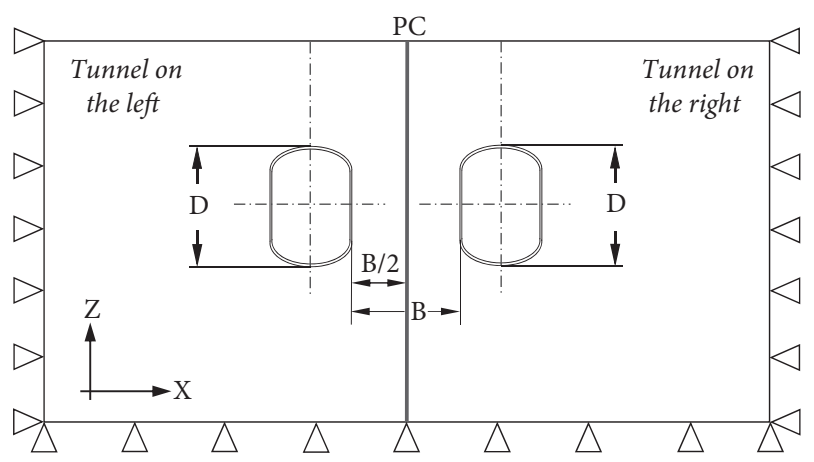

Figure 5: Typical cross-section view of twin tunnels with axis of symmetry PC located between two tunnels (not to scale). Note. $D=$ maximum diameter of horseshoe section $(4 \mathrm{~m})$.

The twin tunnel excavation sequence was modeled starting with the excavation of the first tunnel (left), followed by excavation of the second tunnel (right) with a lagged distance $L_{F}$ behind the face of the first tunnel. The plans of twin tunnel and the typical cross-section excavation process are shown in Figures 4 and 5.

Three different lagged distances $\left(L_{F}=0 \mathrm{D}, 1 \mathrm{D}\right.$, and 2D) between the tunnel on the left and the one on the right were simulated. The case of $L_{F}=0 \mathrm{D}$ corresponds to a situation in which the two tunnel faces are excavated simultaneously in parallel (simultaneously cutting four supporting piles within the excavation range of both tunnels). The $L_{F}=1 \mathrm{D}$ case is equivalent to excavating the left tunnel $4 \mathrm{~m}$ before excavating the right tunnel (first, cutting two supporting piles in the left tunnel area, and then, cutting the other two supporting piles in the right tunnel area).
2.4. Comparison between Numerical Model and Case History. Figure 6 shows a comparison of the measured ground settlement at $G 1$ with the calculation results. The surface settlements recorded from the FE model follow similar patterns as those recorded from the field. The FE model slightly underestimates the surface settlement during construction. This may be attributed to the inherent difficulty of truthfully simulating the excavation process, which is easily affected by many factors. Additionally, the soil properties are highly complex and are also difficult to simulate accurately. Nevertheless, the calculated maximum surface settlement value and its position are in close agreement with the measured data, which provides a sound foundation for further analysis.

The primary goal of this study is to numerically simulate the supporting pile removal effects by the shallow excavation method. The input parameters used in the numerical simulation can be preliminarily considered reasonable and can be used for further comparative analyses of the construction of cutting supporting piles through the shallow excavation method. The numerical simulation trends obtained in this study are in accordance with field monitoring data, so the accuracy of the finite element model is verified.

\section{Analytical Results}

In order to study the mechanical effect of cutting supporting piles during shallow excavation, the trends of surface settlement, pile displacement, and supporting structure internal force were investigated. The numerical simulation sequence is the same as the actual construction process (Table 1) and focuses on the construction process of cutting piles by the shallow excavation method. The numerical model is shown in Figure 3. The moment at which the leftside supporting pile is cut is denoted as "MPL" and that of the right side is denoted as "MPR." The moment of tunnel construction completion is denoted as " $F$ " and the moment the piles are cut simultaneously is denoted as "MP."

3.1. Trend of Surface Settlement around Foundation Pit. The variations in surface settlement were extracted at the section corresponding to the second ring (referred to as the "measured section" from here on). The surface settlement at 


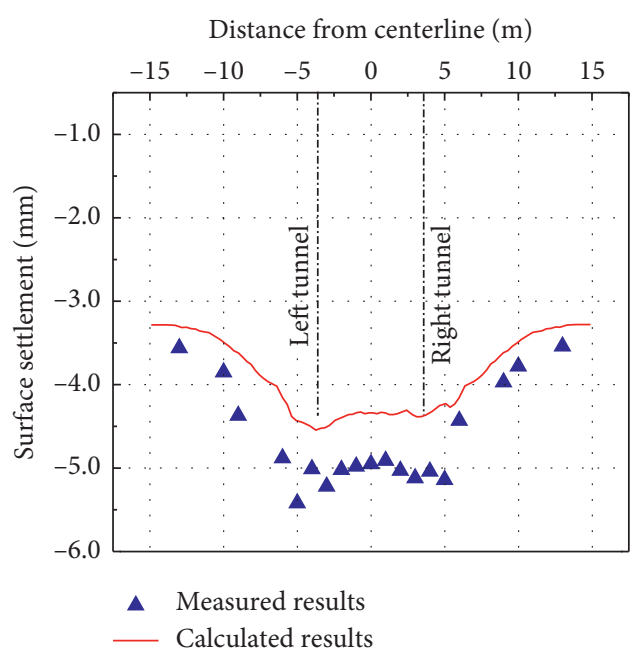

FIGURE 6: Comparison between calculated and measured surface settlement at $G 1$.

the measured section (Figure 4) under different construction conditions is shown in Figure 7. As shown in Figure 7(a), the surface instantaneous settlement above the tunnel axis is about $3.8 \mathrm{~mm}$ with four cut supporting piles and $4.5 \mathrm{~mm}$ when the construction is complete. The surface settlement curve is symmetrical about the center line of the model [35].

In the case of $L_{F}=1 \mathrm{D}$ (Figure 7(b)), the surface settlement mainly occurs around the left tunnel when the supporting piles on the left side are partially cut. There is hardly any settlement of the soil around the right tunnel at this time. When the right supporting piles on the right side are partially cut, settlement of about $2.7 \mathrm{~mm}$ occurs in the soil around the right tunnel and the surface settlement above the left tunnel is slightly larger than that above the right tunnel. The surface settlement continues to increase as the tunnel construction progresses, mainly in the inner area of the double tunnel. The trends of surface settlement under the case of $L_{F}=1 \mathrm{D}$ and the case of $L_{F}=2 \mathrm{D}$ are basically the same.

The evolution of surface settlement of key construction nodes under various construction conditions was analyzed, and the distribution of surface settlement of key construction nodes was obtained, as shown in Figure 8. It can be seen from Figure 8(a) that the maximum surface settlement resulting from the removal of the left-side supporting piles under cases $L_{F}=1 \mathrm{D}$ and $L_{F}=2 \mathrm{D}$ are $2.6 \mathrm{~mm}$ and $2.7 \mathrm{~mm}$, while the maximum surface settlement under $L_{F}=0 \mathrm{D}$ is $3.8 \mathrm{~mm}$ (i.e., about 1.5 times higher than the other cases). This is mainly because the supporting piles in the tunnels on the left and right sides are cut simultaneously in the case of $L_{F}=0 \mathrm{D}$. Thus, the supporting structures have larger damage range, and their rigidity decays rapidly, which causes more surface settlement around the foundation.

As shown in Figure 8(b), the surface settlement curve is asymmetrical and the maximum settlement is above the axis of the left tunnel when the right-side supporting piles are cut in a staggered manner. The surface settlement values are $3.9 \mathrm{~mm}$ (1D) and $4.2 \mathrm{~mm}$ (2D), respectively, both of which are larger than those in the $L_{F}=0 \mathrm{D}$ case. Figure $8(\mathrm{~b})$ shows that the surface settlement curve is asymmetrical and the maximum settlement is above the axis of the left tunnel when the right-side supporting piles are cut by staggered construction. The corresponding values are $3.9 \mathrm{~mm}$ (1D) and $4.2 \mathrm{~mm}(2 \mathrm{D})$, respectively, which are again both larger than those of the surface settlement during synchronous construction. The staggered construction of the tunnel disturbs the stability of the surrounding rock, superimposes the plastic deformation, increases the formation loss, and increases the surface settlement above the left tunnel.

As shown in Figure 8(c), the maximum surface settlement values at the completion of construction under different working conditions are $4.5 \mathrm{~mm}(0 \mathrm{D}), 4.7 \mathrm{~mm}$ (1D), and $4.9 \mathrm{~mm}(2 \mathrm{D})$, respectively. The surface settlement is small in all cases, indicating that shallow-buried excavation with advanced pipe roof reinforcement does not overly disturb the surrounding rock.

In summary, the surface settlement mainly occurs during the process of cutting piles, and the settlement generated by subsequent tunnel construction is about $20 \%$ of the final settlement. The partial pile removal process not only affects the surface settlement but also significantly affects the settlement rate and the shape of the settlement curve. Under three different construction conditions, the ground surface settlement caused by partial supporting piles cutting is mainly distributed within $1 \mathrm{D}$ outside the double tunnel.

\subsection{Bending Moment and Displacement of Supporting Pile.} In order to investigate the changing trend of internal force and displacement of the supporting structure caused by cutting piles, four cut supporting piles were selected as the research objects. For the sake of convenience, the following conditions were placed. (1) One pile of the left tunnel and one pile of the right tunnel under staggered excavation are marked as PL and PR. (2) In the case of $L_{F}=0 \mathrm{D}$, one of the four partially cut piles is selected and marked as $P$. (3) The horizontal displacement of the pile is positive towards the inside of the foundation pit, while the bending moment is positive towards the front side of the pile under tension and negative under compression. The numbers and locations of the piles are shown in Figure 9.

Figure 10 shows the change curve of the bending moment and displacement of the pile under three different construction conditions. The legend symbols PMP and PF represent the bending moment and displacement curve of pile at the time of cutting pile and the final moment of construction under $L_{F}=0 \mathrm{D}$, respectively. PLMPL, PLMPR, and PLF represent the bending moment and displacement curves of PL at the moment of cutting pile from the left tunnel range, cutting pile from the right tunnel range, and construction completion, respectively. The bending moment and displacement curves of PR at different moments have the same description rules as PL.

As shown in Figure 10(a), the distribution of the bending moment of the upper half of the broken pile is similar to that of the simply supported beam under the case $L_{F}=0 \mathrm{D}$ (the supporting piles are simultaneously cut). The maximum bending moment, $510 \mathrm{kN} \mathrm{m}$, occurs at the 

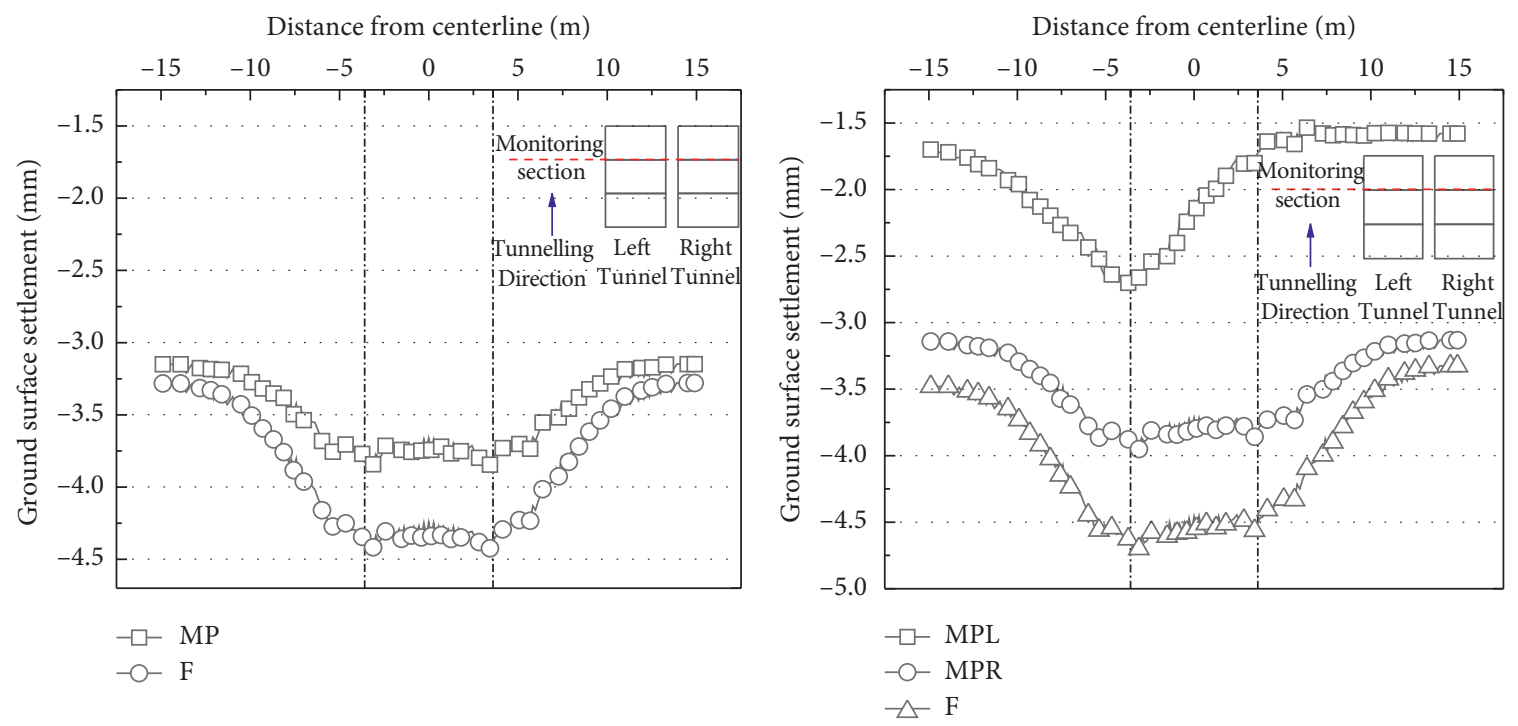

(a)

(b)

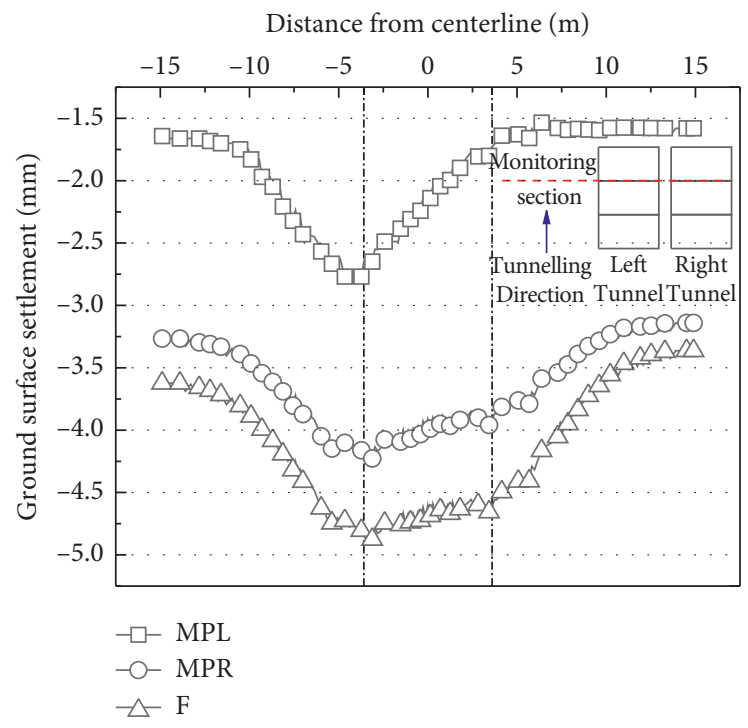

(c)

Figure 7: Surface settlement under different excavation conditions $\left(L_{F}=0 \mathrm{D}, 1 \mathrm{D}\right.$, and 2D).

buried depth of $-6 \mathrm{~m}$. With the continuous excavation of the tunnel, the distribution trend and magnitude of bending moment remain basically unchanged, although the displacement is gradually reduced due to unloading effect. The distribution of the internal force in the lower half of the broken pile is complicated. The bending moment distribution of the downward pile is hyperbolic with the depth. The distribution shape of the bending moment is basically unchanged during tunnel excavation though its total value decreases. The lower half of the broken pile moves towards the excavation side (behind the pile). The displacement of the pile is similar to that of a cantilever pile structure, which suggests that the tunnel excavation exerts an unloading effect on the lower part of the broken pile.

As shown in Figures 10(b) and 10(c), the distribution of the bending moment and displacement of the upper and lower half of the left-side broken pile is similar to the case of $L_{F}=0 \mathrm{D}$ when the left-side piles are cut off. The right-side cut piles show an obvious abrupt flexure within the range of broken pile, and the maximum positive bending moment increases by $17.6 \mathrm{kN} \cdot \mathrm{m}(1 \mathrm{D})$ and $18.2 \mathrm{kN} \cdot \mathrm{m}(2 \mathrm{D})$, respectively. Once construction is complete, the distribution of the bending moment and displacement of the left- and rightside broken piles are basically the same, but the bending moment and displacement of the left-side broken pile are slightly larger than those of the right-side broken pile. This is consistent with the changing trends observed for ground settlement around the foundation.

Based on the above analysis, the stiffness of the supporting structure is weakened when the supporting piles are cut. The upper part of the broken pile is similar to a simplesupported beam structure, and the lower part is similar to a 

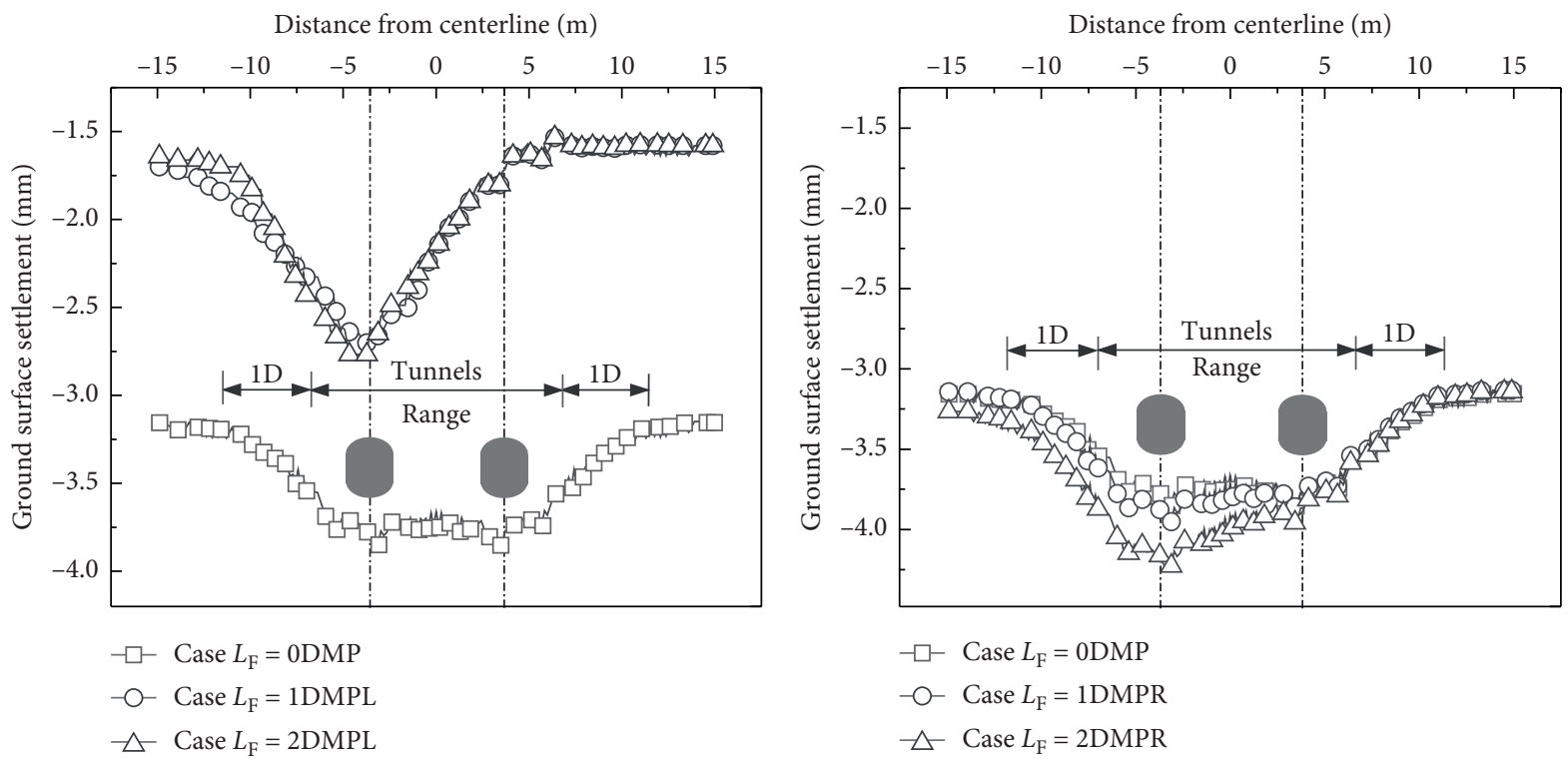

(a)

(b)

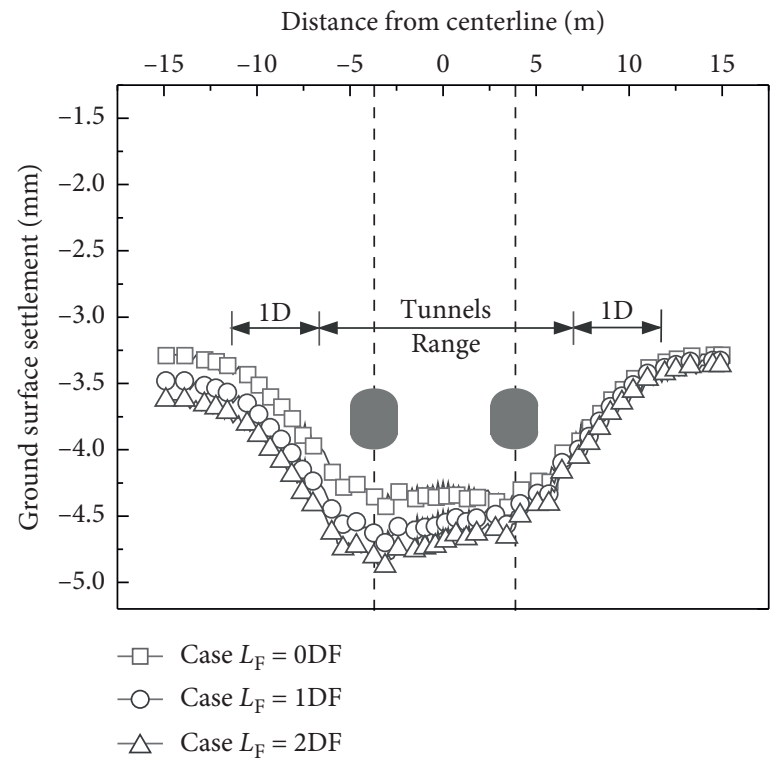

(c)

FiguRE 8: Surface settlement at key construction times while cutting left side of supporting piles, right side of supporting piles, and at construction completion.

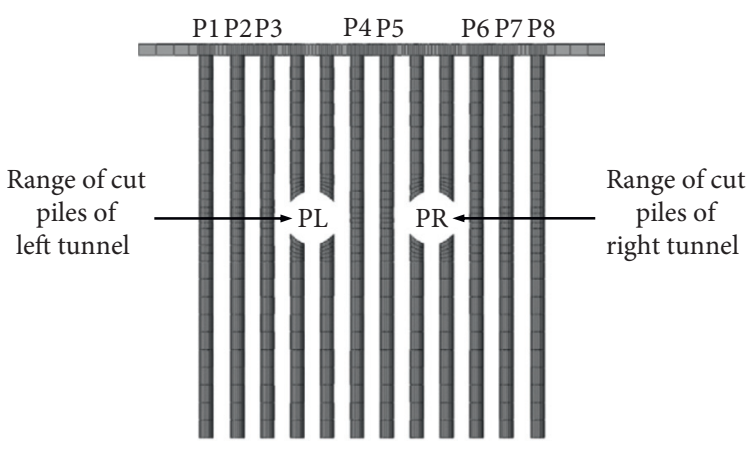

Figure 9: Numbers and locations of piles. 


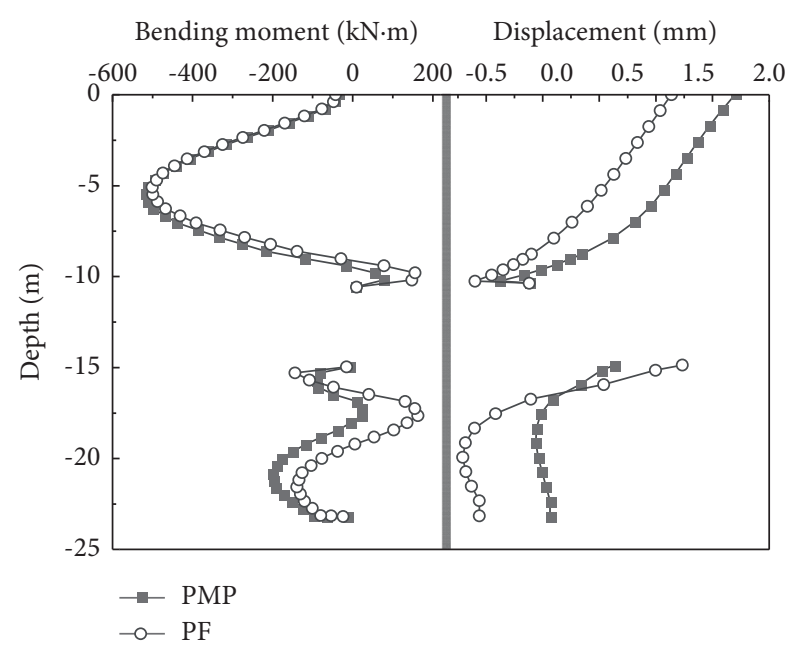

(a)

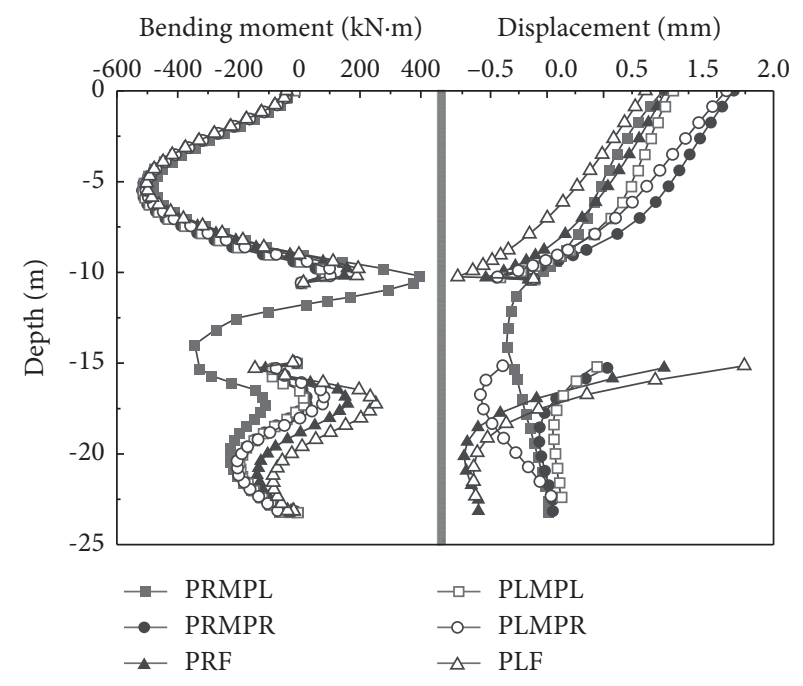

(b)

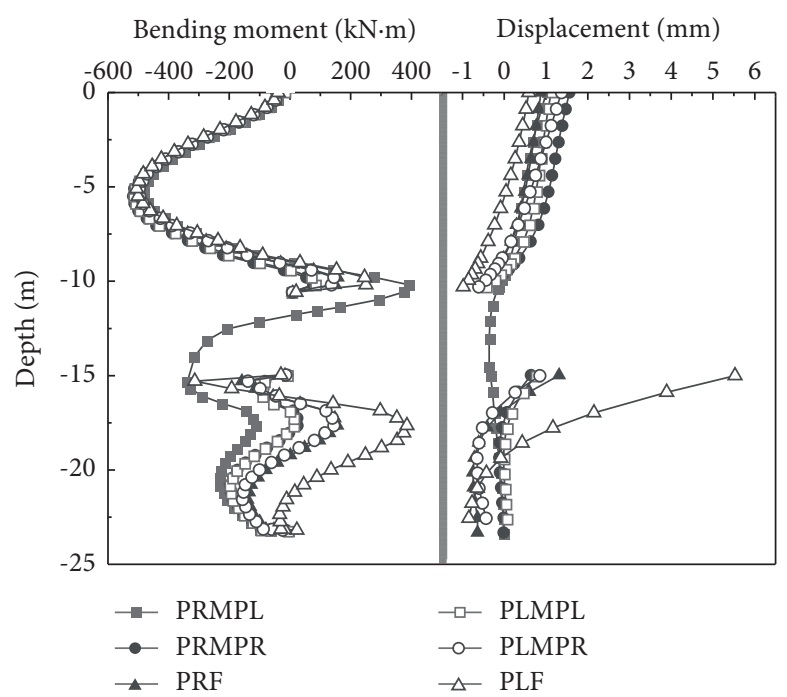

(c)

Figure 10: Bending moment and displacement of piles under different construction conditions $\left(L_{F}=0 \mathrm{D}, 1 \mathrm{D}\right.$, and 2D).

cantilever structure due to the prestressed anchor of the waist beam. Tunnel excavation exerts an unloading effect on the cut pile structure, which leads to a decrease in the bending moment and displacement of the upper and lower parts of the broken pile.

\subsection{Load Transfer Trends of Supporting Piles after Cutting} Piles. After the supporting piles are cut, the stiffness of the supporting structure weakens, the load borne by the cut piles is greatly reduced, and the load is transferred to the adjacent piles. To determine the load transfer trend at work after the supporting piles are partially cut, the bending moment and displacement data of $P 1-P 8$ (Figure 8) were extracted with $L_{F}=1 \mathrm{D}$ as an example. The increased ratios of the pile moment $I_{\mathrm{m}}$ (ratios of peak moments after pile cutting over the moment before cutting the piles) shows that the pile closest to the cut pile range is the most significantly influenced (Figure 11) [36].
Figure 11 shows that the bending moment of the uncut supporting piles adjacent to the shallow-buried cut-off pile area increases to varying degrees during the whole construction process. In the process of cutting PL, part of the transferred load is borne by $P 1 \sim P 4$. In particular, the bending moment of $P 4$ increases the most, to 1.05 times of that before pile cutting. The cutting pile process of PL has little influence on $P 5-P 8$. However, the pile bending moment value of $P 5-P 8$ increases during the process of cutting PR. Besides, the bending moment value of $P 5$ and $P 6$ piles increases greatly. As shallow excavation progresses, the increase ratio of bending moment of $P 4$ and $P 5$ (between the two tunnels) is fastest. The maximum moment increases by about $35 \%$ at the end of the construction process. The maximum moment of $P 3$ and $P 6$ (within the double diameter of the tunnel) increases by about $15 \%$ at the end of construction, whereas the increase in maximum moment of $P 1, P 2, P 7$, and $P 8$ is less than $10 \%$ on the outside of the twin 


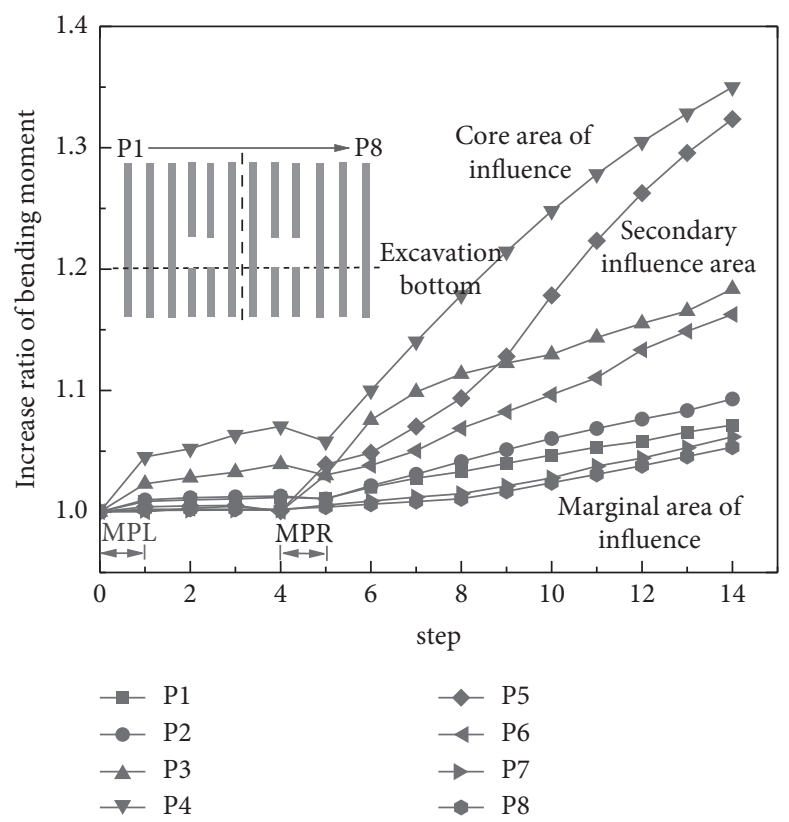

Figure 11: Variation of bending moment $\left(I_{\mathrm{m}}\right)$ when $L_{F}=1 \mathrm{D}$.

tunnel. In this study, according to the $I_{\mathrm{m}}$ value, the influence range of the bending moment of adjacent supporting piles caused by cutting supporting piles can be divided into the following areas: core area of influence $\left(I_{\mathrm{m}}>1.3\right)$, secondary influence area $\left(1.1<I_{\mathrm{m}}<1.3\right)$, and marginal area of influence $\left(I_{\mathrm{m}}<1.1\right)$ (as shown in Figure 11). The maximum bending moment value of the supporting piles in the core area of influence increases the most, indicating that the load is mainly transferred to this area. It can be further concluded that the loading effect caused by the construction of cutting supporting piles is the most significant in this area [37-39].

Cutting supporting piles leads to load transfer, and increasing the load at adjacent supporting piles causes an increase in displacement. In the pile cutting process, the displacement curve of $P 1-P 8$ piles at the depth of $11.2 \mathrm{~m}$ (pile cutting height) is shown in Figure 11 (the displacement is positive toward the inside of the foundation).

Figure 12 shows that the displacement of $P 1-P 4$ occurs towards the inside of the foundation pit. $P 5$ and $P 6$ are also driven by the action of the crown beam and waist beam when $P L$ is cut. $P 1-P 8$ piles show obvious displacement, indicating that the stiffness of the supporting structure system is further weakened when PR is cut. Over the rest of the construction process, the displacement of the P3-P6 piles is relatively large and follows the same trend as the bending moment increase ratio.

To summarize, when the foundation pit supporting piles are cut by the shallow excavation method, the load of the adjacent piles in a diameter range of one time outside the double tunnel increases by about $15 \%$, while the load of the supporting piles in a diameter range of one time inside the double tunnel increases by about $35 \%$. The load is mainly transferred to the supporting piles within a diameter range of one time on both sides of the double tunnel, and the load is not uniformly transferred to the adjacent supporting piles.

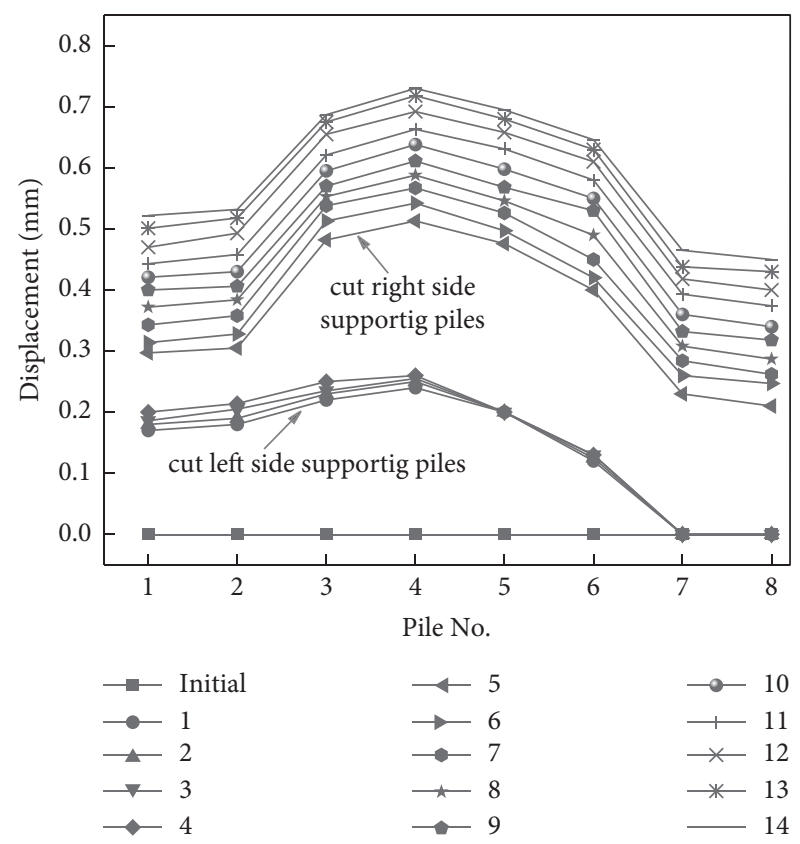

FIgURE 12: Deformation of supporting piles at $11.2 \mathrm{~m}$.

Therefore, in the actual construction process of cutting supporting piles, appropriate reinforcement measures should be adopted for the one-fold diameter range on both sides of the cutting pile area to ensure the stability of the foundation pit.

3.4. Suggestions for Working Conditions of Cutting Supporting Piles. Cutting supporting piles through the shallow excavation method is not conducive to the stability of foundation pit, which brings certain risks to the safety of deep foundation pit 
engineering. In order to ensure the safety of the deep foundation pit which needs pile cutting by the shallow excavation method, several recommendations can be proposed according to the numerical results and practical construction experience. First, considering the influence of construction risk and different tunnel excavation sequences on surface settlement and deformation of supporting piles, $L_{F}=1 \mathrm{D}$ condition has more priority than the other two conditions. Second, because the deep foundation pit of this project is close to existing buildings and the main road of traffic, the surface settlement value generated in the construction process of shallow-buried excavation pile cutting should be controlled in order to reduce the impact of the construction on the surrounding environment. According to the previous construction experience and comprehensive consideration of the construction cost, the diameter of the pipe roof can be appropriately increased or the annular spacing of the pipe roof can be appropriately reduced [40,41]. Third, in order to ensure that the supporting structure still has enough stiffness after the pile cutting, a row of prestressed anchor cables can be installed above the pile cutting area or pile repair can be carried out on both sides of the pile cutting area before cutting piles. With the continuous increase in the utilization rate of urban underground space, cutting supporting piles through shallowburied excavation will be frequently encountered by engineers in practice, which may be more complicated. In order to reduce the pile cutting effect under complex working conditions, additional construction measures should be adopted to ensure the safety of deep foundation pit construction.

\section{Conclusion}

In this study, the characteristics of surface settlement and the mechanical effects of partially cutting supporting piles in a deep excavation structure were investigated using a series of FEM simulations under different working conditions. The model was validated by comparison to a high-quality case.

The main conclusions of this paper can be summarized as follows.

(1) In the partial pile removal process of the shallow excavation method, the surface settlement of the foundation pit mainly occurs when the piles are cut. The surface subsidence produced in the subsequent excavation accounts for about $20 \%$ of the total subsidence. The subsidence is mainly distributed in the area equal to the diameter of the outer twin tunnel.

(2) The different construction modes of cutting supporting piles lead to significant differences in the surface settlement rate and settlement curve shape of the foundation pit. The surface settlements around the foundation under $L_{F}=1 \mathrm{D}$ and $2 \mathrm{D}$ are slightly higher than those under $L_{F}=0 \mathrm{D}$ when the supporting piles are cut, but the curve of the surface settlement varies greatly in the case of $L_{F}=0 \mathrm{D}$. The bending moment and displacement of pile under the case of $L_{F}=1 \mathrm{D}$ are relatively small and can be used as reference for similar projects.

(3) Under three different conditions, the bending moment and displacement of the upper part of the cut piles are similar to those of a simply supported beam structure. The bending moment and displacement of the lower part of the cut piles differ due to the different cutting points, but they all reflect the stress characteristics of the cantilever structure.

(4) After supporting piles are cut, part of the load is mainly transferred to the adjacent supporting piles in the outer half of the tunnel diameter, but the load transfer is not uniform. The load is mainly transferred to the supporting piles between the two holes, and the maximum bending moment of the supporting pile increases by about $35 \%$, which may lead to the failure of the supporting pile. In practical engineering, more attention should be given to the supporting piles adjacent to the area of the twin tunnel diameter.

(5) Different tunnel excavation sequences have a significant influence on surface settlement and deformation characteristics of supporting pile. This study shows that the case of $L_{F}=1 \mathrm{D}$ is more conducive to the stability of the foundation pit.

(6) In order to ensure the safety of deep foundation pit, some reasonable construction measures should be adopted. First, the surface settlement caused by the construction process of cutting supporting piles through shallow-buried excavation should be controlled by appropriately increasing the diameter of the pipe roof or appropriately reducing the annular spacing of the pipe roof. This can control the impact on the surrounding environment during the construction process. Second, reasonable reinforcement measures should be taken before cutting supporting piles to ensure the stability of the foundation pit. A row of prestressed anchor cables can be set above the pile cutting area or the supporting piles can be supplemented on both sides of the pile cutting area.

The above results can be used as a reference for further study on the effect of pile cutting by the shallow excavation method and on the optimization design and reinforcement scheme of the pile-anchor supporting system in foundation pit under the condition of pile cutting. However, the working condition of pile cutting may be more complicated in actual engineering. Therefore, more research on deep foundation pit pile cutting should be carried out in the future to better understand the related effects.

\section{Data Availability}

The data used to support the findings of this study are available from the corresponding author upon request.

\section{Disclosure}

Any opinions, findings, and conclusions or recommendations expressed in this study are those of the authors and do not necessarily reflect the views of the National Natural Science Foundation of China, the Fundamental Research Funds for the Central Universities, and the Research Project 
of Housing and Urban-Rural Development Department of Gansu Province.

\section{Conflicts of Interest}

The authors declare that they no conflicts of interest.

\section{Acknowledgments}

This research was funded by the National Natural Science Foundation of China (Grant nos. 41877285, 42077248, 42077260, and 41941019), the Fundamental Research Funds for the Central Universities, CHD (Grant no. 300102289201), and the Research Project of Housing and Urban-Rural Development Department of Gansu Province (Grant no. JK 2019-03).

\section{References}

[1] T. Schwamb, K. Soga, R. J. Mair et al., "Fibre optic monitoring of a deep circular excavation," Geotechnical Engineering, vol. 167, no. 2, pp. 144-154, 2014.

[2] R. B. Peck, "Deep excavation and tunneling in soft ground. State-of-the-Art report," in Proceedings of the 7th International Conference on Soil Mechanics and Foundation Engineering, pp. 225-325, Mexico City, Mexico, 1969.

[3] T. D. O'Rourke, E. J. Cording, and M. Boscardin, The Ground Movements Related to Braced Excavation and their Influence on Adjacent buildings, National Technical Information Service, Springfield, VA, US, 1976.

[4] M. D. Boscardin, E. J. Cording, and T. D. O’Rourke, Case Studies of Building Behavior in Response to Adjacent excavation, 1978.

[5] T. D. O’Rourke, "Ground movements caused by braced excavations," Journal of the Geotechnical Engineering Division, vol. 107, no. 9, pp. 1159-1178, 1981.

[6] R. J. Finno, D. K. Atmatzidis, and S. B. Perkins, "Observed performance of a deep excavation in clay," Journal of Geotechnical Engineering, vol. 115, no. 8, pp. 1045-1064, 1989.

[7] A. J. Whittle, Y. M. A. Hashash, and R. V. Whitman, "Analysis of deep excavation in Boston," Journal of geotechnical engineering, vol. 119, no. 1, pp. 69-90, 1993.

[8] C. W. W. Ng, "Observed performance of multipropped excavation in stiff clay," Journal of Geotechnical and Geoenvironmental Engineering, vol. 124, no. 9, pp. 889-905, 1998.

[9] M. Long, "Database for retaining wall and ground movements due to deep excavations," Journal of Geotechnical and Geoenvironmental Engineering, vol. 127, no. 3, pp. 203-224, 2001.

[10] R. J. Finno, S. Bryson, and M. Calvello, "Performance of a stiff support system in soft clay," Journal of Geotechnical and Geoenvironmental Engineering, vol. 128, no. 8, pp. 660-671, 2002.

[11] A. T. C. Goh, K. S. Wong, C. I. Teh, and D. Wen, "Pile response adjacent to braced excavation," Journal of Geotechnical and Geoenvironmental Engineering, vol. 129, no. 4, pp. 383386, 2003.

[12] M. A. Soomro, A. Saand, N. Mangi, D. A. Mangnejo, H. Karira, and K. Liu, "Numerical modelling of effects of different multipropped excavation depths on adjacent single piles: comparison between floating and end-bearing pile responses," European Journal of Environmental and Civil Engineering, pp. 1-31, 2019.
[13] C. W. W. Ng, N. Simons, and B. Menzies, Soil-structure engineering, Thomas Telford, London, UK, 2004.

[14] Y. Liu, B. Xiang, and M. Fu, "Observed performance of a large-scale deep triangular excavation in shanghai soft clays," Geotechnical and Geological Engineering, vol. 37, no. 4, pp. 2791-2809, 2019.

[15] T. D. O'Rourke and A. J. McGinn, "Lessons learned for ground movements and soil stabilization from the Boston Central Artery," Journal of Geotechnical and Geoenvironmental Engineering, vol. 132, no. 8, pp. 966-989, 2006.

[16] E. H. Y. Leung and C. W. W. Ng, "Wall and ground movements associated with deep excavations supported by cast in situ wall in mixed ground conditions," Journal of Geotechnical and Geoenvironmental Engineering, vol. 133, no. 2, pp. 129-143, 2007.

[17] Y. M. A. Hashash, A. Osouli, and C. Marulanda, "Central artery/tunnel project excavation induced ground deformations," Journal of Geotechnical and Geoenvironmental Engineering, vol. 134, no. 9, pp. 1399-1406, 2008.

[18] Y. Tan and M. Li, "Measured performance of a $26 \mathrm{~m}$ deep topdown excavation in downtown Shanghai," Canadian Geotechnical Journal, vol. 48, no. 5, pp. 704-719, 2011.

[19] M. Ali Soomro, N. Mangi, H. Xiong, M. Kumar, and D. Ali Mangnejo, "Centrifuge and numerical modelling of stress transfer mechanisms and settlement of pile group due to twin stacked tunnelling with different construction sequences," Computers and Geotechnics, vol. 121, Article ID 103449, 2020.

[20] Z. Xu, L. Zong, J. Shen, and W. Wang, "Deformation of a deep excavation adjacent to metro tunnels in soft soils," Chinese Journal of Geotechnical Engineering, vol. 41, no. S1, pp. 41-44, 2019.

[21] P.-G. Hsieh and C.-Y. Ou, "Simplified approach to estimate the maximum wall deflection for deep excavations with cross walls in clay under the undrained condition," Acta Geotechnica, vol. 11, no. 1, pp. 177-189, 2016.

[22] M. A. Soomro, N. Mangi, D. A. Mangnejo, and N. A. Memon, "3D centrifuge and numerical modelling of lateral responses of a vertical loaded pile group to twin stacked tunnels," European Journal of Environmental and Civil Engineering, pp. 1-28, 2021.

[23] M. Shakeel and C. W. W. Ng, "Settlement and load transfer mechanism of a pile group adjacent to a deep excavation in soft clay," Computers and Geotechnics, vol. 96, pp. 55-72, 2018.

[24] X. Zhang, J. Yang, Y. Zhang, and Y. Gao, "Cause investigation of damages in existing building adjacent to foundation pit in construction," Engineering Failure Analysis, vol. 83, pp. 117124, 2018.

[25] P. Guo, X. Gong, and Y. Wang, "Displacement and force analyses of braced structure of deep excavation considering unsymmetrical surcharge effect," Computers and Geotechnics, vol. 113, Article ID 103102, 2019.

[26] S. Liu, J. Yang, J. Fu, and X. Zheng, "Performance of a deep excavation irregular supporting structure subjected to asymmetric loading," International Journal of Geomechanics, vol. 19, no. 7, Article ID 05019007, 2019.

[27] X. Gao, W.-p. Tian, and Z. Zhang, "Analysis of deformation characteristics of foundation-pit excavation and circular wall," Sustainability, vol. 12, no. 8, Article ID 3164, 2020.

[28] National Bureau of Standards of China (NBS), Steel Strand for Prestressed concrete (GB/T 5224-2014), NBS, Beijing, China, 2014.

[29] K. Zhang and Y. Ai, "Comparison and application of different elasto-plastic constitutive models in fem analysis of an 
excavated soil slope," Journal of Civil Engineering and Management, vol. 18, no. 6, pp. 802-810, 2012.

[30] K.-y. Zhang and F. N. Charkley, "An anisotropic constitutive model of geomaterials based on true triaxial testing and its application," Journal of Central South University, vol. 24, no. 6, pp. 1430-1442, 2017.

[31] Y. Hejazi, D. Dias, and R. Kastner, "Impact of constitutive models on the numerical analysis of underground constructions," Acta Geotechnica, vol. 3, no. 4, pp. 251-258, 2008.

[32] S. Liao, Y. Fan, Z. Shi, W. Shao, and X. Kong, "Optimization study on the reconstruction and expansion of an underground rail transit center in Shanghai soft ground," Tunnelling and Underground Space Technology, vol. 38, pp. 435-446, 2013.

[33] C.-Y. Ou, P.-G. Hsieh, and Y.-L. Lin, "A parametric study of wall deflections in deep excavations with the installation of cross walls," Computers and Geotechnics, vol. 50, pp. 55-65, 2013.

[34] J. Duriez and É. Vincens, "Constitutive modelling of cohesionless soils and interfaces with various internal states: an elasto-plastic approach," Computers and Geotechnics, vol. 63, pp. 33-45, 2015.

[35] M. A. Soomro, M. Kumar, H. Xiong, D. A. Mangnejo, and N. Mangi, "Investigation of effects of different construction sequences on settlement and load transfer mechanism of single pile due to twin stacked tunnelling," Tunnelling and Underground Space Technology, vol. 96, Article ID 103171, 2020.

[36] X. S. Cheng, G. Zheng, Y. Diao et al., "Study of the progressive collapse mechanism of excavations retained by cantilever contiguous piles," Engineering Failure Analysis, vol. 71, pp. 72-89, 2017.

[37] X. S. Cheng, G. Zheng, Y. Diao et al., "Experimental study of the progressive collapse mechanism of excavations retained by cantilever piles," Canadian Geotechnical Journal, vol. 54, no. 4, pp. 574-587, 2017.

[38] K. Choosrithong and H. F. Schweiger, "Influence of individual strut failure on performance of deep excavation in soft soil," in Proceedings of China-Europe Conference on Geotechnical Engineering, pp. 316-319, Springer, Vienna, Austria, August 2018.

[39] A. T. C. Goh, Z. Fan, L. Hanlong, Z. Wengang, and Z. Dong, "Numerical analysis on strut responses due to one-strut failure for braced excavation in clays," in Proceedings of the 2nd International Symposium on Asia Urban GeoEngineering, pp. 560-574, Springer, Changsha, China, November 2018.

[40] X. Xie, M. Zhao, and I. Shahrour, "Experimental study of the behavior of rectangular excavations supported by a pipe roof," Applied Sciences, vol. 9, no. 10, Article ID 2082, 2019.

[41] R. Hasanpour, H. Chakeri, Y. Ozcelik, and H. Denek, "Evaluation of surface settlements in the Istanbul metro in terms of analytical, numerical and direct measurements," Bulletin of Engineering Geology and the Environment, vol. 71, no. 3, pp. 499-510, 2012. 